\title{
Antihypertensive Therapy Considering the Prevention of Vascular Aging
}

\author{
Toshihiko Ishimitsu, MD \\ Department of Hypertension and Cardiorenal Medicine, Dokkyo Medical University, Mibu, Tochigi, Japan
}

\section{| ABSTRACT |}

Considering that an aging population is increasing due to a low birth rate in most developed nations, the maintenance of healthy state and physical and social activities is needed to maintain the national productivities. Among the diseases which deprive elderly people of activities and impose medical and care expenditure, cardiovascular diseases such as stroke, ischemic heart disease, heart failure and renal failure take major parts. These cardiovascular diseases occur based on the development and progression of arteriosclerotic vascular lesions, namely, vascular aging. Because hypertension is a major risk factor for vascular aging, the adequate control of blood pressure is pivotally important in order to prevent the incidence of cardiovascular events in the later stage of life. This is also concerned with the socio-economical issues and national productivity.

(J Korean Soc Hypertens 2011;17(3):85-94)

Key Words: Hypertension; Vascular aging; Atherosclerosis; Antihypertensive drugs

\section{Lifestyle-related diseases and vascular aging}

The ultimate goal of antihypertensive therapy is not only to normalize the blood pressure level but also to prevent the cardiovascular disease such as stroke and coronary artery disease and to prevent organ damage such as renal dysfunction and cardiac failure. These cardiovascular organ injuries progress based on the development of arteriosclerosis, namely vascular aging. Fig. 1 depicts the process from the lifestyle-related disorders to arteriosclerosis development resulting in the occurrence of cardiovascular diseases and organ failures. Hypertension is a major factor which contributes to the progression of arte-

논문접수일: 2011. 8. 24, 수정완료일: 2011. 9. 10, 게재승인일: 2011. 9. 14 교신저자: Toshihiko Ishimitsu, MD

주소: Department of Hypertension and Cardiorenal Medicine, Dokkyo Medical University, Mibu, Tochigi 321-0293, Japan

Tel: +81-282-87-2149, Fax: +81-282-86-6186

E-mail: isimitu@dokkyomed.ac.jp riosclerosis, however, other lifestyle-related diseases such as diabetes mellitus and dyslipidemia synergistically promote the arteriosclerotic process.

When considering the risk of vascular aging, the idea of metabolic syndrome (Met-S) has been recognized widely. Namely, elevations in blood pressure and/or blood glucose below the diagnosis criteria for hypertension and diabetes mellitus when accompanied by waist circumference expansion and dyslipidemia offer a significant increase in the risk of cardiovascular diseases. ${ }^{1,2)}$ In Met-S, the waist circumference increase is brought about by the deposition of visceral fat especially in men. The visceral fat produces mediators such as angiotensinogen, transforming growth factor-alpha, registin and free fatty acids which facilitate the development of hypertension, diabetes mellitus and dyslipidemia. On the other hand, the production of adiponectin, which has protective 
effects against cardiovascular tissue and organ injuries, decreases in the accumulated visceral fat tissue in Met-S.

\section{Blood pressure elevation and vascular aging}

Epidemiological studies have indicated that there is a linear relationship between blood pressure and the risk of cardiovascular diseases such as stroke and myocardial infarction. ${ }^{3)}$ This relationship also exists even in the normal blood pressure range below 140/90 $\mathrm{mm} \mathrm{Hg}$ down to $115 / 75 \mathrm{~mm} \mathrm{Hg}$. Considering that the pathogenesis of these cardiovascular diseases are based on the development and progression of arteriosclerosis, vascular aging, strict blood pressure control to the lower level even in the normotensive range is desirable in terms of slowing the progression of vascular aging. Therefore, the latest versions of various guidelines for the management of hypertension recommend reduction of the blood pressure below the high end of the normal range, i.e., lower than 130/85 mm Hg, in non-elderly hypertensive patients. ${ }^{4-6)}$
In particular, patients with complications such as diabetes mellitus and chronic kidney disease (CKD) need stricter blood pressure control $(<130 / 80 \mathrm{~mm} \mathrm{Hg})$ in order to prevent the progression of vascular aging consequently felling into target organ damage and cardiovascular diseases.

Multiple factors, including genetic and environmental influences, are known to contribute to the development and continuation of high blood pressure. Especially, an increase in body fluid volume caused by decreased urinary sodium excretion and an increase in peripheral vascular resistance caused by structural thickening and/or functional constriction of small arteries play pivotal roles in the pathogenesis of hypertension. Most etiological factors of hypertension elicit blood pressure elevation through affecting these two major mechanisms. It seems obvious that vascular aging increases peripheral vascular resistance and reduces renal function when happens in the renal arteries and arterioles. Thus, vascular aging and blood pressure elevation are interrelated each other. Hypertension aggravates arteriosclerosis and vice versa. It

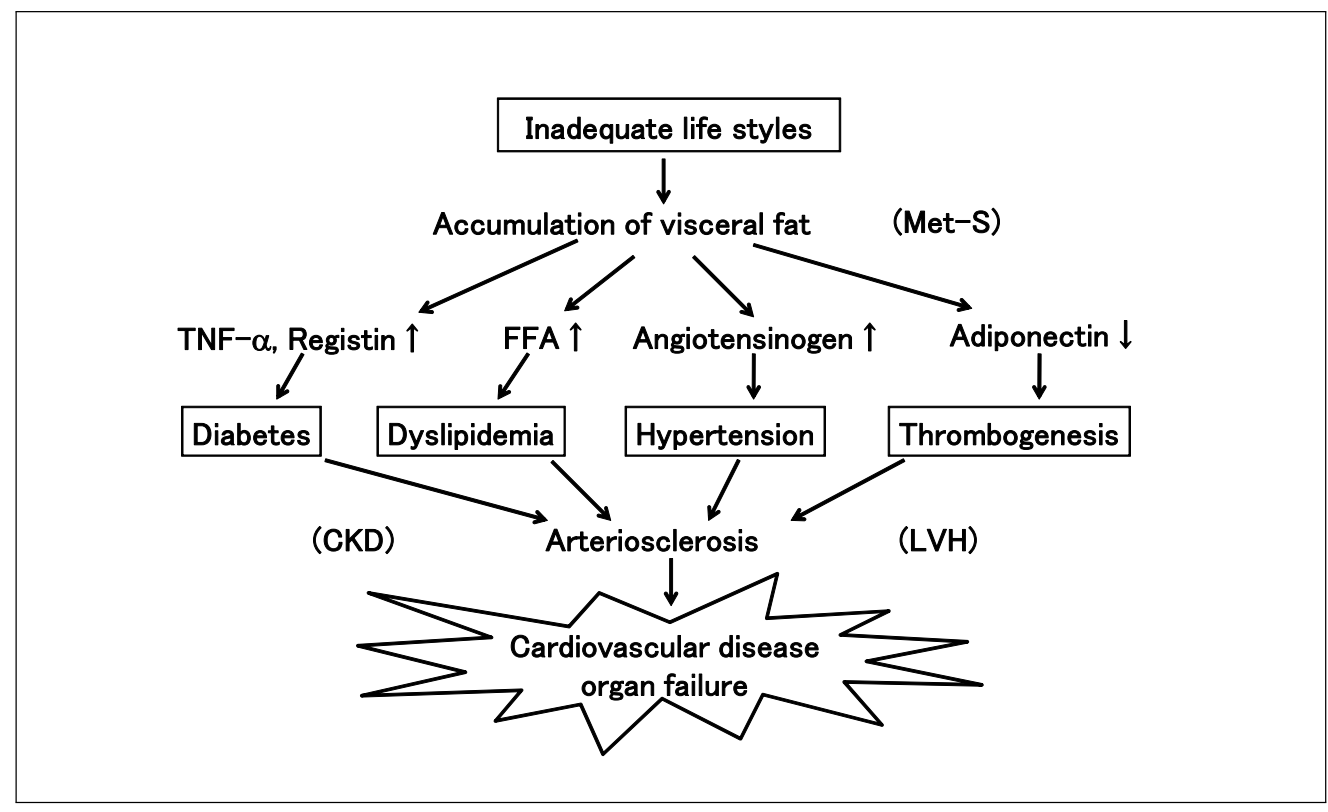

Fig. 1. Cascade from the life-style related diseases to the occurrence of cardiovascular diseases via risk factors and vascular aging. Met-s, metabolic syndrome; TNF- $\alpha$, chronic kidney disease; FFA, free fatty acid; CKD, chronic kidney disease; LVH, left ventricular hypertrophy. 
is essential to cut off this vicious cycle to pervert blood pressure elevation, vascular aging and resultant cardiovascular disorders.

\section{Renin-angiotensin-aldosterone system in vascular aging}

Looking from the other viewpoint, neurohumoral factors are greatly involved in the maintenance of homeostasis of cardiovascular functions including blood pressure regulation. Among them, the sympathetic nerve system and the renin-angiotensin-aldosterone (RAA) system play pivotal roles in the regulation of blood pressure and the pathogenesis of hypertension. The seconds to minutes range swift variation of blood pressure is mainly controlled by the sympathetic nerve activity. As compared with this, the RAA system takes charge of rather more chronic changes in blood pressure.

Fig. 2 presents the outlines of RAA system. Among the factors of RAA system, angiotensin II and aldosterone have prominent biological actions such as arteriolar con- striction and promotion of sodium reabsorption by the renal tubules. Besides these pro-hypertensive actions, angiotensin II has been shown to exhibit non-hemodynamic effects such as stimulating sympathetic nerve system, promoting cardiovascular hypertrophy, reducing insulin sensitivity, facilitating thrombus formation, increasing oxidative stress and eliciting cardiovascular tissue inflammation. ${ }^{7,8)}$ Moreover, aldosterone also has been shown to promote cardiovascular cellular hypertrophy, endothelial dysfunction, blood coagulation, cardiovascular tissue fibrosis and inflammation. These detrimental effects of angiotensin II and aldosterone, in addition to the blood pressure elevation, are supposed to accelerate the progression of vascular aging.

\section{Oxidative stress and inflammation in the process of vascular aging}

Cardiovascular disease arises due to the progression of arteriosclerosis, vascular aging. Laboratory and experimental evidence has indicated that chronic inflammation has a

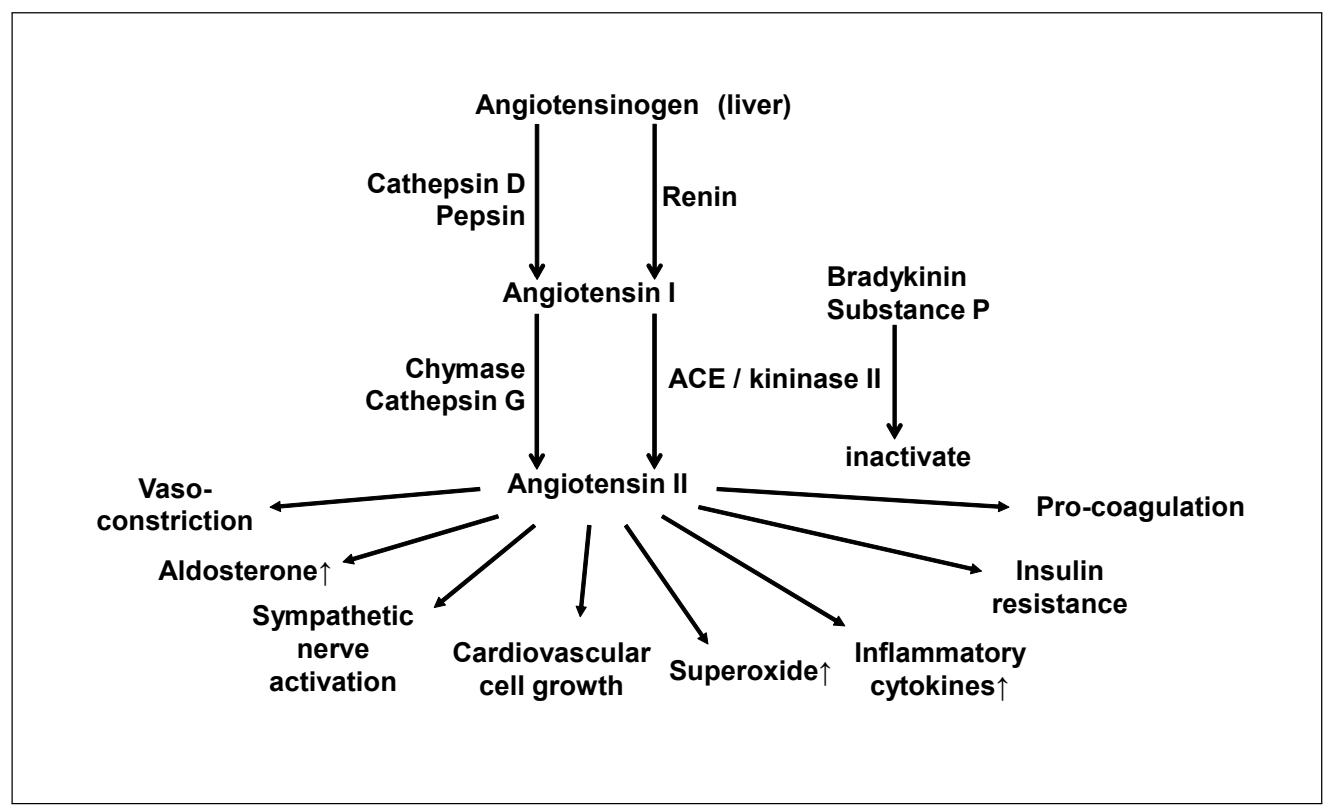

Fig. 2. Outlines of the renin-angiotensin-aldosterone system and its biological actions. ACE, angiotensin-converting enzyme. 
role in the development of arteriosclerosis. ${ }^{9,10)}$ A number of studies have examined various circulating markers of inflammation, such as cytokines and adhesion molecules, as potential predictors of the existence and future risk of cardiovascular disease. Among the numerous circulating markers thus far studied, high-sensitivity C-reactive protein (hsCRP) seems to have the most consistent relation with the risk of cardiovascular diseases in a variety of clinical settings including hypertension. ${ }^{11-13)}$

In addition to the classical risk factors for arteriosclerosis, such as hypertension and dyslipidemia, oxidative stress has been attracting considerable attention as one of the novel risk factors for cardiovascular injury. Oxidative stress depletes nitric oxide and cause endothelial dysfunction that initiates arteriosclerosis. Oxidized low-density lipoprotein (LDL) generated by oxidative stress also promotes the progression of arteriosclerosis. ${ }^{14-16)}$ As described earlier, enhancement of the RAA system is supposed to increase oxidative stress and elicit inflammation in the cardiovascular tissues. Namely, angiotensin II increases oxidative stress by activating nicotinamide adenine dinucleotide-phosphate (NAD $[\mathrm{P}] \mathrm{H})$ oxidase, and induce proinflammatory transcription factor NF- $\mathrm{B}_{k}{ }^{17,18)}$ Thus, it is surmised that various cardiovascular risk factors elicit these biochemical and immunological reactions which bring about cardiovascular tissue lesions and injuries including vascular aging.

\section{Evaluation of vascular aging}

The process of arteriosclerosis is initiated by the occurrence of endothelial dysfunction. Vascular endothelium produces vasoactive substances including vasoconstrictive factors such as endothelin and vasodilative factors such as nitric oxide (NO) and prostacyclin. Among them, NO, also known as the endothelim-derived relaxing factor (EDRF), is promptly released in response to various nox- ious stimuli and is thought to play important roles in maintain the integrity of vascular system. Endothelial function is evaluated by measuring the vasodilation and blood flow increase in the forearm after certain minutes of arterial occlusion using ultrasound or plethysmography.

Solid changes in arterial wall caused by hypertension and aging are thickening and stiffening of media. Such changes in arterial wall can be clinically evaluated by physiological examination and ultrasound technique. Pulse wave velocity (PWV) is an indicator of arterial stiffness and an increased PWV has been shown to reflect a higher risk of cardiovascular disease. ${ }^{19,20)}$ However, it has been pointed out that the PWV varies according to the changes of blood pressure and sympathetic activity. ${ }^{7,21)}$ The cardio-ankle vascular index (CAVI) is calculated by adjusting PWV for blood pressure based on a stiffness parameter $(\beta)$ and is thought to be a more accurate index of arterial stiffness. ${ }^{22,23)}$

\section{Chronic kidney disease and vascular aging}

It has been now recognized that the existence of CKD imposes a great risk not only for the progression of renal failure but also for the development of cardiovascular diseases and thereby worsens the life prognosis. ${ }^{24)}$ Considering that the kidney is rich in vessels including glomeruli, it seems natural to assume that the vascular aging develops in the cardiovascular system including brain, heart and peripheral arteries in parallel with the renal vasculature. Therefore, in the treatment of CKD patients, the strict control of blood pressure is primarily needed in order to prevent deterioration of renal function and progression of cardiovascular organ injuries based on the vascular aging. ${ }^{25)}$ However, hypertension in CKD tends to be resistant to therapy because the renal dysfunction is involved in the etiology, ${ }^{26}$ and multiple antihypertensive drugs are often required for the blood pres- 
sured reduction.

Fig. 3 shows the changes in the parameters of renal function with the progression of renal injuries. In the early stage of renal dysfunction, renal blood flow (RBF) and plasma flow (RPF) decrease by the development of renal vascular lesions such as glomerulosclerosis. However, this is not accompanied by a decrease in glomerular filtration rate (GFR) because of a compensatory increase in filtration fraction (FF). A reduction in GFR and an elevation of serum creatinine does not occur until the renal function deteriorates to a considerable extent. Development of renal vascular lesions causes obliteration of glomerular arterioles and abolition of connecting nephrons. Once a certain proportion of nephrons fall into atrophy, the intraglomerular capillary pressure and the single nephron filtration rate of remaining glomeruli increase in order to compensate the reduced RBF and maintain GFR, which consequently promote further development of glomerular hypertension and arteriolar injuries.

The increased urinary albumin excretion is thought to reflect an elevation of intraglomerular capillary pressure and endothelial dysfunction which allows the permeation of small protein molecules. Accordingly, the existence of microalbuminuria, at an early stage of renal dysfunction and vascular aging, before presenting overt proteinuria possibly indicates the risk of future cardiovascular disease incidence as well as deterioration of renal function. A number of studies have indicated that increased urinary excretion of albumin is a predictor of future cardiovascular events in hypertensive patients and in general population. $^{27-30)}$

\section{Antihypertensive drug therapy for preventing vascular aging}

It is mentioned that the strict blood pressure control is desirable in order to maximally prevent the progression of vascular aging. However, only one third of hypertensive patients achieve such strict target blood pressure levels with a single antihypertensive agent irrespective of the class of drug used and thus two thirds of patients require a combination of two or more drugs in order to obtain adequate blood pressure reduction. ${ }^{31,32)}$ When combining multiple antihypertensive drugs, the mechanism of

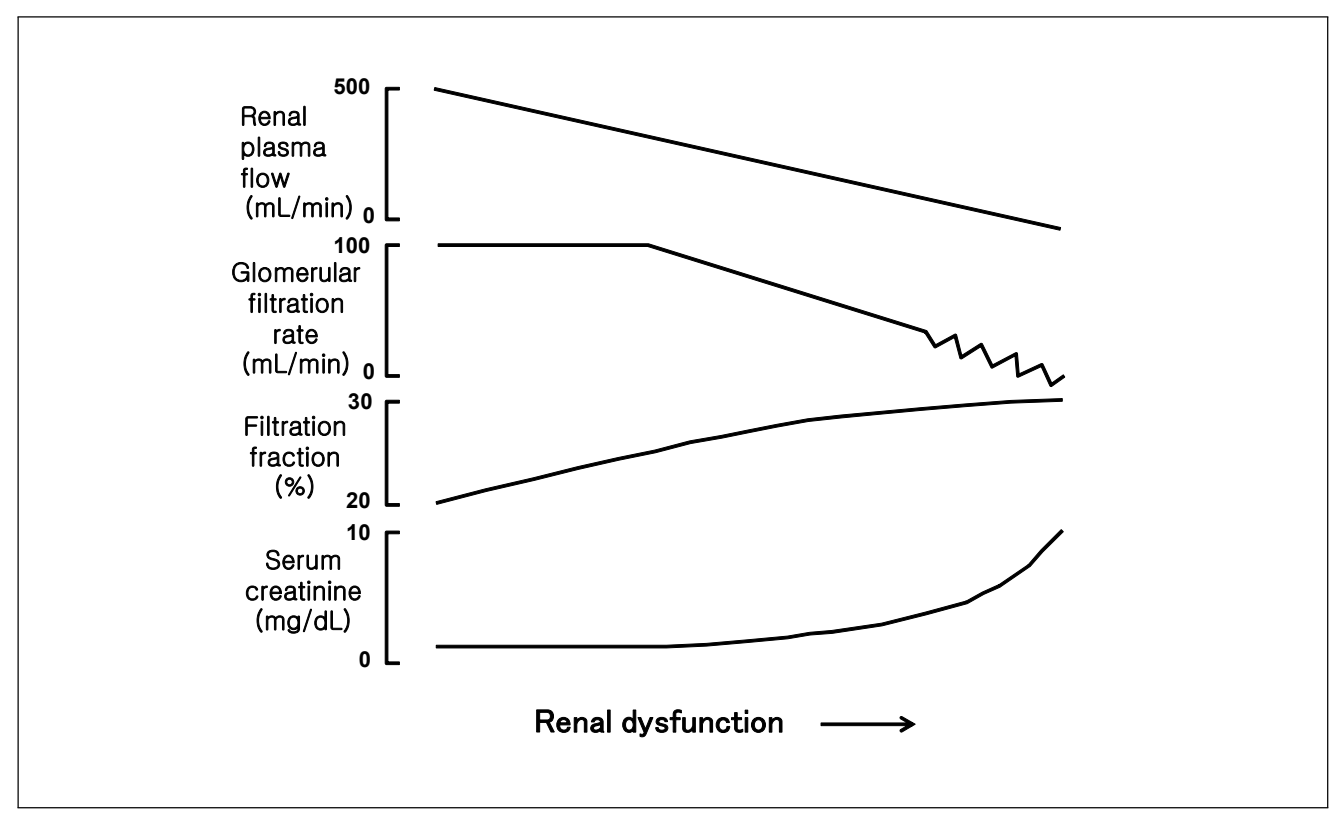

Fig. 3. Changes in the parameters of renal function along with the progression of renal dysfunction. 
action and adverse effects should be thoroughly understood in order to attain the maximum benefit from combination therapy. It is desirable for the antihypertensive effect to be enhanced and the adverse effects to be canceled by combining different classes of antihypertensive drugs.

Several large-scale clinical trials have compared the long-term effects of combination antihypertensive drug therapies in hypertensive patients. The Anglo-Scandinavian Cardiac Outcomes Trial-Blood Pressure Lowering Arm (ASCOT-BPLA) compared $\beta$-blocker (atenolol) + thiazide diuretic and calcium channel blocker (CCB) (amlodipine) + angiotensin-converting enzyme (ACE) inhibitor (perindopril) in high-risk hypertensive patients. ${ }^{33)}$ The latter combination offered less stroke, coronary events and death than the former combination, and later analysis showed that the aortic central blood pressure is higher in the $\beta$ -blocker/thiazide group than in the $\mathrm{CCB} / \mathrm{ACE}$ inhibitor group. ${ }^{34)}$ Considering that the central blood pressure wave is formed by the summation of cardiac ejection wave and reflection wave from the peripheral arteries, the combination of $\mathrm{CCB}$ and renin-angiotensin system inhibitor (RASI) is thought to have advantage in mitigating vascular aging and slowing the reflection wave transmission.

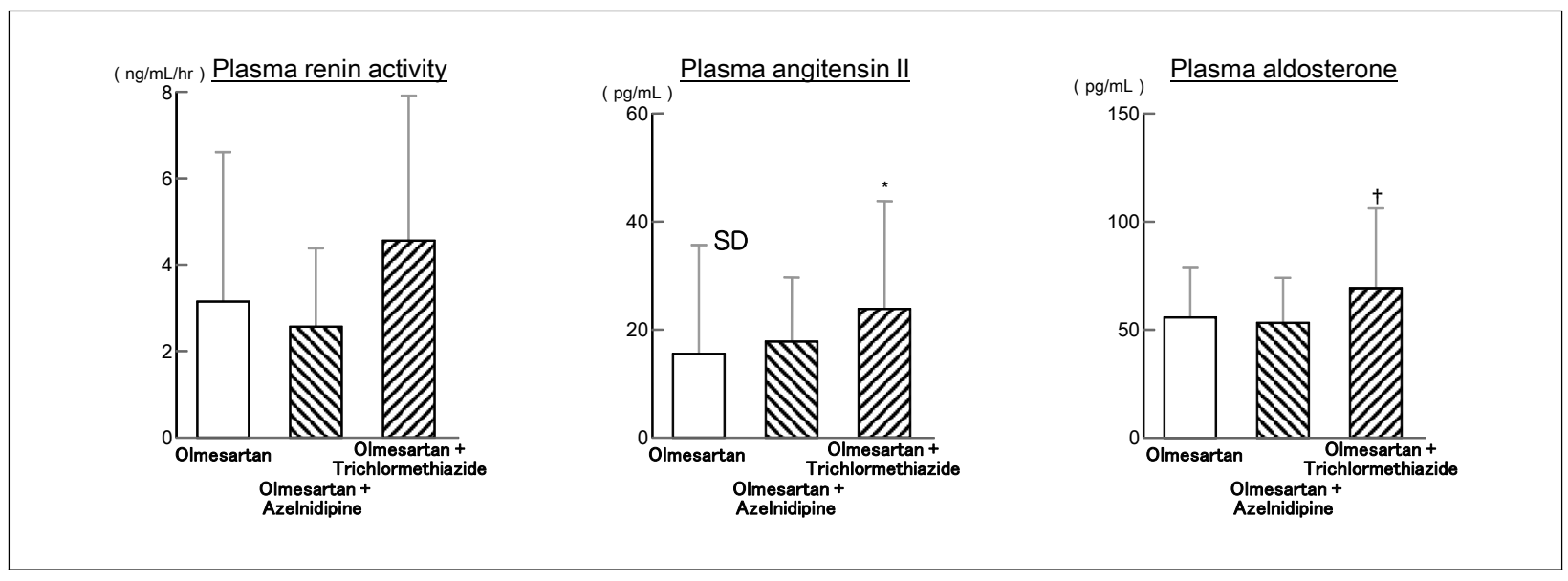

Fig. 4. Circulating components of renin-angiotensin-aldosterone system in hypertensive patients given the combination of angiotensin $\|$ receptor antagonist (olmesartan) with thiazide or calcium channel blocker (azelnidipine). ${ }^{*} p<0.05,{ }^{\dagger} p<0.01$.

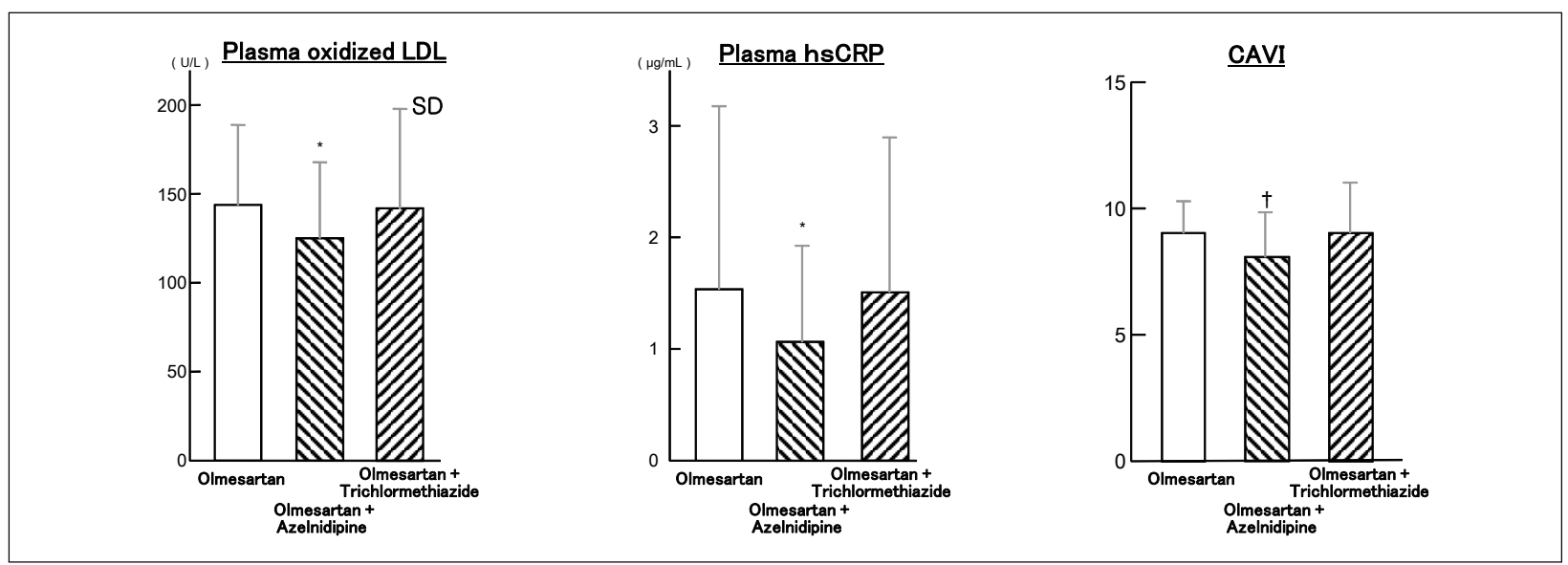

Fig. 5. Markers of oxidative stress, inflammation and arterial stiffness in hypertensive patients given the combination of angiotensin II receptor blocker with thiazide or calcium channel blocker. LDL, low-density lipoprotein. hsCRP: high-sensitivity C-reactive protein, CAVI: cardio-ankle vascular index. ${ }^{*} p<0.05,+p<0.01$. 
In the Avoiding Cardiovascular Events through Combination Therapy in Patients Living with Systolic Hypertension (ACCOMPLISH) trial, ${ }^{35)}$ high-risk hypertensive patients were treated by the combination of $\mathrm{ACE}$ inhibitor (benazepril) with thiazide diuretic or CCB (amlodipine), and the incidence of cardiovascular events was $20 \%$ less in the RASI/CCB combination than in the RASI/thiazide combination. Although the albuminuria reduction was more prominent in the RASI/thiazide, GFR was better preserved in the RASI/CCB and the deterioration of renal function was $48 \%$ less in the RASI/ $\mathrm{CCB}^{36)}$ When we treated hypertensive patients with the combination of angiotensin II receptor blocker (ARB) (olmesartan) and thiazide or with the combination of $\mathrm{ARB}$ and $\mathrm{CCB}$ (azelnidipine), circulating components of RAA system such as plasma renin activity, plasma angiotensin II (Ang II) and aldosterone were enhanced by the thiazide combination (Fig. 4). ${ }^{37)}$ On the other hand, plasma oxidized LDL, a marker of oxidative stress, and hsCRP, an inflammatory marker, were lowered by the CCB combination (Fig. 5). Furthermore, CAVI, an index of arterial wall stiffness, was lowered by the CCB combination. Dihydropyridine $\mathrm{CCB}$, besides directly relaxing the arterial smooth muscle, has been shown to have antioxidant activity in vitro. ${ }^{38)}$ Therefore, the RASI/
CCB combination seems to cause less RAA system activation, reduction in oxidative stress and suppression of inflammatory process resulting in the alleviation of vascular aging and stiffening.

Regarding the CKD patients, The Gauging Albuminuria Reduction With Lotrel in Diabetic Patients With Hypertension (GUARD) trial $^{39)}$ treated the hypertensive patients with type 2 diabetes presenting albuminuria with CCB (amlodipine) or thiazide diuretic combined with the same ACE inhibitor (benazepril) and showed that albuminuria was more prominently reduced by the thiazide combination and GFR was better preserved by the CCB combination like the results of ACCOMPLISH trial. In our clinical trial comparing ARB (losartan) + thiazide and ARB + CCB (nifedipine) in CKD patients, GFR was higher, serum LDL-cholesterol was lower and the CAVI was lower in the $\mathrm{CCB}$ combination treatment than in the thiazide combination treatment (Fig. 6). ${ }^{40)}$ Thus, also in CKD patients, the combination antihypertensive drug therapy with RASI and CCB is supposed to offer protective effects against vascular aging and deterioration of renal function.

\section{Summary and conclusion}

In order to prevent cardiovascular diseases and car-
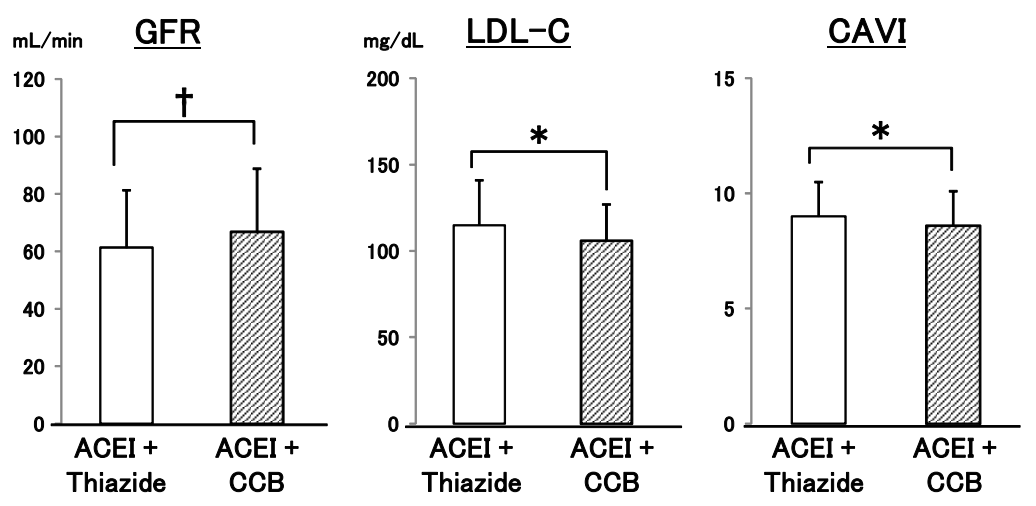

Fig. 6. Glomerular filtration rate (GFR), serum low-density lipoprotein-cholesterol (LDL-C) and cardio-ankle vascular index (CAVI) in hyperteisive chronic kidney disease patients given the combination of angiotensin-converting enzyme inhibitor (ACEI) with thiazide or calcium channel blocker (CCB). ${ }^{*} p<0.05,{ }^{\dagger} p<0.01$. 
diovascular organ injuries, it is important to inhibit the progression of vascular aging such as arteriosclerosis and atherosclerosis, because cardiovascular diseases such as stroke and myocardial infarction occur based on the development of these vascular lesions. Hypertension is a pivotal risk factor for the vascular aging and the strictly low target blood pressure level is needed to achieve maximal protection of cardiovascular system. Care should be also taken for other risk factors such as diabetes and dyslipidemia. In addition, nonclassical risk factors such as the RAA system, oxidative stress and inflammation may take part in the progression of vascular aging. In most cases, the combination of multiple antihypertensive drugs is needed to achieve strict blood pressure control. According to the late clinical studies, the RASI + CCB combination seems advantageous over the RASI + thiazide combination in terms of avoiding the RAA system stimulation, reducing oxidative stress, avoiding cardiovascular tissue inflammation, reducing arterial stiffness and slowing the vascular aging.

According to the analyses of epidemiological studies, even $1 \mathrm{~mm} \mathrm{Hg}$ difference in systolic blood pressure can affect the incidence of cardiovascular events. Therefore, the strict blood pressure control throughout 24 hours is needed to maximally reduce the risk of cardiovascular diseases. However, some recent studies suggest the possibilities of J-curve phenomenon in the presence of certain disorders such as diabetes and coronary artery disease. ${ }^{41,42)}$ These may be derived from the vascular lesions or dysfunction which is not necessarily parallel to the changes in blood pressure. Moreover, novel cardiovascular risk factors such as insulin resistance, Met-S and CKD are conceivably based on structural and functional abnormalities in muscular, adipose tissues and the kidneys in part. Thus, in addition to the management of blood pressure level, qualitative advance of future antihypertensive ther- apy is supposed to be promoted by incorporating the functional (endothelial function, arterial stiffness), biochemical (oxidative stress, inflammation) and morphological (intimal plaques, calcification) evaluations of vascular system.

\section{References}

1. Isomaa B, Almgren P, Tuomi T, Forsen B, Lahti K, Nissen $\mathrm{M}$, et al. Cardiovascular morbidity and mortality associated with the metabolic syndrome. Diabetes Care. 2001;24:683-9.

2. Safar ME, Thomas F, Blacher J, Nzietchueng R, Bureau JM, Pannier B, et al. Metabolic syndrome and age-related progression of aortic stiffness. J Am Coll Cardiol. 2006;47:72-5.

3. Lewington S, Clarke R, Qizilbash N, Peto R, Collins R; Prospective Studies Collaboration. Age-specific relevance of usual blood pressure to vascular mortality: a meta-analysis of individual data for one million adults in 61 prospective studies. Lancet. 2002; 360:1903-13.

4. Chobanian AV, Bakris GL, Black HR, Cushman WC, Green LA, Izzo JL Jr, et al. The Seventh Report of the Joint National Committee on Prevention, Detection, Evaluation, and Treatment of High Blood Pressure: the JNC 7 report. JAMA. 2003;289:2560-72.

5. Mancia G, De Backer G, Dominiczak A, Cifkova R, Fagard R, Germano G, et al. 2007 Guidelines for the management of arterial hypertension: The Task Force for the Management of Arterial Hypertension of the European Society of Hypertension (ESH) and of the European Society of Cardiology (ESC). Eur Heart J. 2007;28: 1462-536.

6. Ogihara T, Kikuchi K, Matsuoka H, Fujita T, Higaki J, Horiuchi M, et al. The Japanese Society of Hypertension Guidelines for the Management of Hypertension (JSH 2009). Hypertens Res. 2009;32:3-107.

7. Struthers AD, MacDonald TM. Review of aldosteroneand angiotensin II-induced target organ damage and prevention. Cardiovasc Res. 2004;61:663-70.

8. Schmieder RE, Hilgers KF, Schlaich MP, Schmidt BM. Renin-angiotensin system and cardiovascular risk. Lancet. 2007;369:1208-19.

9. Kuller LH, Tracy RP, Shaten J, Meilahn EN. Relation of 
C-reactive protein and coronary heart disease in the MRFIT nested case-control study. Multiple Risk Factor Intervention Trial. Am J Epidemiol. 1996;144:537-47.

10. Schillaci G, Pirro M. C-reactive protein in hypertension: clinical significance and predictive value. Nutr Metab Cardiovasc Dis. 2006; 16:500-8.

11. Hage FG, Szalai AJ. C-reactive protein gene polymorphisms, C-reactive protein blood levels, and cardiovascular disease risk. J Am Coll Cardiol. 2007;50:1115-22.

12. Steinberg D, Parthasarathy S, Carew TE, Khoo JC, Witztum JL. Beyond cholesterol. Modifications of lowdensity lipoprotein that increase its atherogenicity. N Engl J Med. 1989;320:915-24.

13. Witztum JL, Steinberg D. Role of oxidized low density lipoprotein in atherogenesis. J Clin Invest. 1991;88:1785-92.

14. Mertens A, Holvoet P. Oxidized LDL and HDL: antagonists in atherothrombosis. FASEB J. 2001;15:2073-84.

15. Nada T, Nomura M, Koshiba K, Kawano T, Mikawa J, Ito S. Clinical study with azelnidipine in patients with essential hypertension. Antiarteriosclerotic and cardiac hypertrophy-inhibitory effects and influence on autonomic nervous activity. Arzneimittelforschung. 2007;57:698-704.

16. Ohmura C, Watada H, Shimizu T, Sakai K, Uchino H, Fujitani Y, et al. Calcium channel blocker, azelnidipine, reduces lipid hydroperoxides in patients with type 2 diabetes independent of blood pressure. Endocr J. 2007;54:805-11.

17. Remuzzi G, Perico N, Macia M, Ruggenenti P. The role of renin-angiotensin-aldosterone system in the progression of chronic kidney disease. Kidney Int Suppl. 2005:S57-65.

18. Brewster UC, Setaro JF, Perazella MA. The reninangiotensin-aldosterone system: cardiorenal effects and implications for renal and cardiovascular disease states. Am J Med Sci. 2003;326:15-24.

19. London GM, Marchais SJ, Guerin AP, Pannier B. Arterial stiffness: pathophysiology and clinical impact. Clin Exp Hypertens. 2004;26:689-99.

20. Matsui Y, Kario K, Ishikawa J, Eguchi K, Hoshide S, Shimada K. Reproducibility of arterial stiffness indices (pulse wave velocity and augmentation index) simultaneously assessed by automated pulse wave analysis and their associated risk factors in essential hypertensive patients. Hypertens Res. 2004;27:851-7.
21. Ito N, Ohishi M, Takagi T, Terai M, Shiota A, Hayashi N, et al. Clinical usefulness and limitations of brachial-ankle pulse wave velocity in the evaluation of cardiovascular complications in hypertensive patients. Hypertens Res. 2006;29:989-95.

22. Takaki A, Ogawa H, Wakeyama T, Iwami T, Kimura M, Hadano $Y$, et al. Cardio-ankle vascular index is superior to brachial-ankle pulse wave velocity as an index of arterial stiffness. Hypertens Res. 2008;31:1347-55.

23. Smith DH, Dubiel R, Jones M. Use of 24-hour ambulatory blood pressure monitoring to assess antihypertensive efficacy: a comparison of olmesartan medoxomil, losartan potassium, valsartan, and irbesartan. Am J Cardiovasc Drugs. 2005;5:41-50.

24. Go AS, Chertow GM, Fan D, McCulloch CE, Hsu CY. Chronic kidney disease and the risks of death, cardiovascular events, and hospitalization. N Engl J Med. 2004;351: 1296-305.

25. Bakris GL, Williams M, Dworkin L, Elliott WJ, Epstein M, Toto R, et al. Preserving renal function in adults with hypertension and diabetes: a consensus approach. National Kidney Foundation Hypertension and Diabetes Executive Committees Working Group. Am J Kidney Dis. 2000;36: 646-61.

26. Campese VM, Mitra N, Sandee D. Hypertension in renal parenchymal disease: why is it so resistant to treatment? Kidney Int. 2006;69:967-73.

27. Bigazzi R, Bianchi S, Baldari D, Campese VM. Microal buminuria predicts cardiovascular events and renal insufficiency in patients with essential hypertension. J Hypertens. 1998;16:1325-33.

28. Jensen JS, Feldt-Rasmussen B, Strandgaard S, Schroll M, Borch-Johnsen K. Arterial hypertension, microalbuminuria, and risk of ischemic heart disease. Hypertension. 2000;35: 898-903.

29. Yuyun MF, Khaw KT, Luben R, Welch A, Bingham S, Day NE, et al. Microalbuminuria independently predicts all-cause and cardiovascular mortality in a British population: The European Prospective Investigation into Cancer in Norfolk (EPIC-Norfolk) population study. Int J Epidemiol. 2004;33:189-98.

30. Klausen K, Borch-Johnsen K, Feldt-Rasmussen B, Jensen G, Clausen P, Scharling H, et al. Very low levels of microalbuminuria are associated with increased risk of 
coronary heart disease and death independently of renal function, hypertension, and diabetes. Circulation. 2004; 110:32-5.

31. Elliott WJ. Is fixed combination therapy appropriate for initial hypertension treatment? Curr Hypertens Rep. 2002;4:278-85.

32. Mori H, Ukai H, Yamamoto H, Saitou S, Hirao K, Yamauchi $\mathrm{M}$, et al. Current status of antihypertensive prescription and associated blood pressure control in Japan. Hypertens Res. 2006;29:143-51.

33. Dahlof B, Sever PS, Poulter NR, Wedel H, Beevers DG, Caulfield M, et al. Prevention of cardiovascular events with an antihypertensive regimen of amlodipine adding perindopril as required versus atenolol adding bendroflumethiazide as required, in the Anglo-Scandinavian Cardiac Outcomes Trial-Blood Pressure Lowering Arm (ASCOT-BPLA): a multicentre randomised controlled trial. Lancet. 2005;366:895-906.

34. Williams B, Lacy PS, Thom SM, Cruickshank K, Stanton A, Collier D, et al. Differential impact of blood pressurelowering drugs on central aortic pressure and clinical outcomes: principal results of the Conduit Artery Function Evaluation (CAFE) study. Circulation. 2006;113:1213-25.

35. Jamerson K, Weber MA, Bakris GL, Dahlof B, Pitt B, Shi $\mathrm{V}$, et al. Benazepril plus amlodipine or hydrochlorothiazide for hypertension in high-risk patients. N Engl J Med. 2008;359:2417-28.

36. Bakris GL, Sarafidis PA, Weir MR, Dahlof B, Pitt B, Jamerson K, et al. Renal outcomes with different fixeddose combination therapies in patients with hypertension at high risk for cardiovascular events (ACCOMPLISH): a prespecified secondary analysis of a randomised controlled trial. Lancet. 2010;375:1173-81.

37. Ishimitsu T, Numabe A, Masuda T, Akabane T, Okamura A, Minami J, et al. Angiotensin-II receptor antagonist combined with calcium channel blocker or diuretic for essential hypertension. Hypertens Res. 2009;32:962-8.

38. Lupo E, Locher R, Weisser B, Vetter W. In vitro antioxidant activity of calcium antagonists against LDL oxidation compared with alpha-tocopherol. Biochem Biophys Res Commun. 1994;203:1803-8.

39. Bakris GL, Toto RD, McCullough PA, Rocha R, Purkayastha D, Davis P, et al. Effects of different ACE inhibitor combinations on albuminuria: results of the GUARD study. Kidney Int. 2008;73:1303-9.

40. Ishimitsu T, Ohno E, Nakano N, Furukata S, Akashiba A, Minami J, et al. Combination of angiotensin II receptor antagonist with calcium channel blocker or diuretic as antihypertensive therapy for patients with chronic kidney disease. Clin Exp Hypertens. 2011;33:366-72.

41. Messerli FH, Mancia G, Conti CR, Hewkin AC, Kupfer S, Champion A, et al. Dogma disputed: can aggressively lowering blood pressure in hypertensive patients with coronary artery disease be dangerous? Ann Intern Med. 2006; 144:884-93.

42. Cooper-DeHoff RM, Gong Y, Handberg EM, Bavry AA, Denardo SJ, Bakris GL, et al. Tight blood pressure control and cardiovascular outcomes among hypertensive patients with diabetes and coronary artery disease. JAMA. 2010;304:61-8. 